\title{
Actual Problems of Geosynchronous Elliptical Orbits Application for Service the Russian Federation Territory
}

\author{
Maxim S. Tsimbal* \\ Academician M.F. Reshetnev Information Satellite Systems \\ 52 Lenin Str., Zheleznogorsk, \\ Krasnoyarsk region, 662972, Russia
}

Received 11.11.2014, received in revised form 21.12.2014, accepted 16.04.2015

The task of providing advanced communications and broadcasting services for terrestrial subscribers in the entire territory of the Russian Federation cannot be solved without using satellites on the high elliptical orbits. The article highlights a number of problematic issues that need to be resolved during the development of advanced satellite mobile and direct broadcasting systems using the orbits of this type.

Keywords: Highly Elliptical Orbits (HEO), satellite communications, satellite broadcasting

\section{Актуальные вопросы применения \\ геосинхронных эллиптических орбит \\ для обслуживания территории Российской Федерации}

\author{
М.С. Цимбал \\ $A O$ «Информационные спутниковые системыл» \\ имени академика М.Ф. Решетнёва» \\ Россия, 662972, Железногорск, Ленина, 52
}

\begin{abstract}
Задача предоставления современных услуг связи и вещания для наземных абонентов на всей территории Российской Федерации не может быть решена без использования спутниковретрансляторов на высоких эллиптических орбитах. В статье выделен ряд проблемных вопросов, подлежащих решению в ходе создания перспективных систем спутниковой персональной связи и непосредственного вещания с использованием орбит этого типа.
\end{abstract}

Ключевые слова: высокоэллиптическая орбита, спутниковая связь, спутниковое радиовещание.

(C) Siberian Federal University. All rights reserved

* Corresponding author E-mail address: office@iss-reshetnev.ru 
В последние годы в нашей стране наблюдается повышение интереса к исследованиям в области использования высокоэллиптических орбит (ВЭО) и появляется ряд новых предложений по её применению для спутниковых систем связи различного назначения [1]. Данный интерес можно объяснить совокупностью нескольких факторов:

- невозможность обслуживания приполярных территорий с геостационарной орбиты (ГСО) и её перегруженность вследствие имеющихся природных ограничений;

- возобновление исследовательской активности в приполярных районах;

- благоприятные условия, сложившиеся к настоящему моменту вследствие развития ряда ключевых - космических, электронных, телекоммуникационных - технологий;

- потребность в создании единого информационного пространства на всей территории России и приграничных областях.

Как известно, изначально системы космической связи, построенные с использованием ВЭО типа «Молния», применялись в системе телевизионного вещания «Орбита», для которой на территории СССР была создана обширная сеть станций с антеннами диаметром 12 м, оснащённых системами слежения за космическими аппаратами (КА) [2].

Анализ работ на эту тему показывает, что, несмотря на имеющийся в нашей стране опыт использования орбитальной группировки «Молния», отсутствует практический задел по созданию спутниковых систем, предназначенных для предоставления высококачественных услуг персональной связи и непосредственного телерадиовещания. Спецификой спутниковых систем этого типа является обслуживание высокомобильных абонентов на обширной территории, что обусловливает необходимость использования в абонентском терминале малогабаритной ненаправленной антенны [2, 3].

При создании спутниковых систем на ВЭО, предназначенных для предоставления мобильных услуг, на первое место выходят проблемы, связанные с обеспечением максимальной зоны радиовидимости [4] и поддержанием необходимой энергетики в трассах распространения сигнала на расстояниях 40000 км.

Также важный аспект данного типа систем - это подверженность каналов связи воздействию общих и многолучевых замираний при распространении сигналов на участках радиолинии из-за наличия многократных отражений и изменения взаимного положения земной станции относительно спутника-ретранслятора.

Сопутствующим фактором, дополнительно осложняющим приём радиосигнала, можно считать изменение частоты принимаемого сигнала вследствие эффекта Доплера, возникающего по причине перемещения КА относительно абонента.

Как правило, в описании предлагаемых отечественных спутниковых систем на ВЭО в качестве примера приводят успешную реализацию системы радиовещания Sirius, предоставляющей услуги на территории Северной Америки $[5,6]$. Однако не принимается во внимание, что успех данной системы состоялся благодаря достижению основной цели - предоставление доступной и качественной услуги максимальному количеству населения на обслуживаемой территории. Причём доступность в данном случае следует считать ключевой составляющей, которая обеспечивается простым в применении и недорогим абонентским оборудованием, а также приемлемой абонентской платой за потребляемый контент. Качественная же составляющая должна обеспечиваться реализацией максимально возможного энергетического по-

$$
-347-
$$


тенциала радиолинии и организации вещания с многоуровневыми комбинациями способов доставки и обработки сигнала.

Успешное функционирование на протяжении уже более десятка лет систем непосредственного радиовещания Sirius и XM-Radio в США подтверждает правильность такого подхода - решения только одной возложенной на систему задачи, но выполняемой этой системой максимально эффективно. Для службы спутникового непосредственного радиовещания любые попытки сделать систему многозадачной, и поэтому в чём-то компромиссной, приведут к неминуемому снижению интереса со стороны потенциальных потребителей вследствие усложнения приёмной части абонентского оборудования [7].

Таким образом, можно выделить несколько первоочередных научно-технических задач, подлежащих решению в процессе создания систем спутниковой персональной связи и непосредственного радиовещания с использованием ВЭО:

1. Обеспечение больших значений углов места радиовидимости КА, позволяющих обеспечить уверенный круглосуточный приём на всей области обслуживания. Данная задача должна решаться путём выбора оптимальных параметров орбиты и количества КА.

2. Необходимость создания достаточно высокого уровня плотности потока мощности у поверхности Земли и вблизи КА (в случае персональной связи). Здесь выдвигаются максимальные требования к излучаемой мощности, которая имеет ограничения, обусловленные энергетическими возможностями бортового оборудования КА и терминала абонента. Эти возможности в первую очередь определяются системой электропитания, а также эффективностью передающей аппаратуры и антенной системы. Очевидно, что для систем персональной связи задача должна решаться с применением многолучевых крупноаппертурных бортовых антенн $[8,9]$, а для систем вещания решением должно послужить использование контурных антенн с наведением.

При обслуживании обширной территории Российской Федерации и прилегающих областей задачи обеспечения достаточных значений углов места и уровня плотности потока мощности, при ограниченных возможностях бортовых систем КА, становятся особенно трудновыполнимыми. Решением данной проблемы может послужить построение спутниковой системы на базе двух независимых орбитальных группировок (ОГ) типа «Тундра» [10] с использованием в каждой не менее трёх спутников-ретрансляторов. Предполагается, что каждая из ОГ предназначена для работы в западной и восточной зонах обслуживания РФ. При таком варианте построения системы практически на всей территории РФ обеспечивается значение углов места не менее $60^{\circ}$, что создает высокую вероятность приёма сигнала, особенно в местах со сложным рельефом местности.

Несмотря на необходимость использования двух дополнительных КА, по сравнению с вариантом ОГ типа «Молния», несомненными достоинствами такого подхода являются:

- возможность реализации потребительских характеристик системы на высоком качественном уровне, близком к зарубежным аналогам вследствие увеличения, по меньшей мере в два раза, энергетического потенциала в обслуживаемой зоне;

- возможность поэтапного ввода системы в эксплуатацию;

- возможность организации разделения вещания с учётом разных часовых поясов и региональных особенностей; 
- снижение вероятности общей неработоспособности системы по причине выхода из строя одного КА.

3. Разработка эффективных методов борьбы с общими и многолучевыми замираниями для повышения надёжности и достоверности передачи сообщений. Решению данной задачи могут способствовать следующие меры:

- использование сложных помехоустойчивых сигналов с применением высокоэффективных кодов;

- различные виды разнесения сигналов по приёму и передаче по параметрам времени, частоте, пространству, поляризация или их комбинации;

- поиск оптимальных методов и алгоритмов приёма, адаптированных к каналам с переменными параметрами, учитывающих наличие как общих, так и многолучевых замираний. При выборе способа построения приёмного устройства в заданных условиях потребуется конкретизация и соответствующая модификация существующих моделей каналов с переменными параметрами.

\section{Список литературы}

[1] Выгонский Ю.Г., Кузовников А.В., Головков В. // Спутниковые технологии и бизнес. 2014 C. 2430.

[2] Камнев Е.Ф., Акимов А.А., Бобков В.Ю. и др. Системы спутниковой связи с эллиптическими орбитами, разнесением ветвей и адаптивной обработкой. М.: Глобсатком, 2009. 724 с.

[3] Камнев В.Е., Черкасов В.В., Чечин Г.В. Спутниковые сети связи: Учеб. пособие. 2-е изд., доп. М.: ООО «Военный парад», 2010. 608 с.

[4] Акимов А.А. // Электросвязь. 1998. № 2. С. 10-21.

[5] Крылов А.М. // Состояние и перспективы развития. 2014.

[6] Крылов А.М., Локиин Б.А. // Телевидение и радиовещание. 2009. № 2. С. 26-29.

[7] Локшин Б.А., Орлов Ю. // Телевидение и радиовещание. № 4-5. 2013 С. 48-49.

[8] Выгонский Ю.Г., Мухин В.А., Кузовников А.В., Сомов В.Г. // Фундаментальные исследования. 2014. № 9. С. 965-970.

[9] Акимов А., Полищук В., Шевчук Д. // Спутниковая связь и вещание. Специальный выпуск. 2014. С. 44-49.

[10] Акимов А., Шевчук Д., Чазов В. // Технологии и средства связи. 2014. № 3. С. 50-56.

[11] Материалы сайта www.wikipedia.com. 